\title{
An Overview of English Writing Research in Taiwan
}

\author{
Li-hua Chou \& Denis Michael Hayes \\ National Taiwan Ocean University \\ E-mail: lihua506@mail.ntou.edu.tw
}

\begin{abstract}
This study systematically investigates the English writing research in Taiwan, over the span of time from 1989 to 2008, a 19-year time period. Data collection consisted of five major sources. Guided by Juzwik et al's (2006) study, the data were analyzed based on the general problems under investigated, the age groups being researched, the methodologies being implemented, and types of research being conducted at different grade levels. Findings revealed that writing instruction, writing and technologies and peer evaluation were the most studied problems in writing research whereas collaborative writing, error analysis, and cultural influences were the least studied problems. The most studied populations were university and senior high school students while the least studied groups were kindergarteners and adults. Most studies were conducted by using qualitative methodology. Writing and technologies was the most studied type of research among elementary school students and university students, whereas writing instruction was frequently studied among senior high school students, graduate students and adult students. The implications and recommendations that emerge out of these results provide possible agendas for writing teachers, researchers and policy makers worldwide.
\end{abstract}

Keywords: Overview of English writing research, Writing instruction, General problems, Age groups, Methodology

\section{Introduction}

Among the systematic review of English as the first language (L1) writing research, several studies have been published in the United States. However, systematic review of English as a foreign language (EFL) writing research has seldom become the central focus of literature. The reason could be that the review of EFL writing research would involve many non-English speaking countries around the world; therefore, to systematically and thoroughly examine the abundance of published articles related to EFL writing would be a difficult task. Nevertheless, systematical examination of EFL writing research from an EFL speaking country would help fill the gap in the body of FL writing research. This study systematically analyzes and investigates EFL writing research outside the United States. It focuses on the trends and foci of English writing research in Taiwan over the span of time from 1989 to 2008, a 19-year period. The purpose of this study is threefold. First, it helps to fill the gap in the body of foreign language writing research and helps writing instructors, writing researchers, and curriculum developers worldwide to develop the understanding of English writing research in an EFL learning environment. Second, Chinese writing researchers tend to have partial understanding about the bits and pieces of information concerning English writing research conducted in their country. This paper is intended to assist writing researchers to familiarize themselves with research conducted within nearly two decades in Taiwan. Third, it points out a possible future direction for EFL writing research agendas.

\section{Review of literature}

Previous research on the overview of English writing in L1 and L2 was conducted by a few scholars in the United States. With regard to the overview of EFL writing research, little information can be acquired in the body of existing literature. It is important to be acquainted with the overview of L1 and L2 writing research because FL writing research has been heavily influenced by L1 and L2 writing research (O'Brien, 2004). Furthermore, English language writing instruction for native speakers has also influenced EFL writing instruction (You, 2006). Accordingly, the writers of L2/EFL are very similar to English native speakers in the respect of learning to write (Williams, 2005).

Among the L1 writing researchers, Hillocks (1984) first conducted a meta-analysis of experimental treatment studies on teaching composition in the United States. The study was an integrative review of experimental studies from 1963 to 1982. In this review, Hillocks investigated experimental studies conducted over this time span by including studies that involved treatments, uses of writing quality scale applied to writing samples, exercises of minimal control for teacher bias, controls for differences among groups of subjects, and insurances on the validity and reliability of the scored compositions. In synthesizing the experimental studies, Hillocks examined the treatments, including four modes of instruction: presentational mode, natural process mode, environmental mode and individualized mode. Hillock's study provides us an insightful view pertaining to what factors of effective writing instruction should be taken into account when teaching writing.

Following Hillocks' studies, Herrington (1989) also published an article entitled the First Twenty Years of Research in the Teaching of English and the Growth of a Research Community in Composition Studies. By using Research in the Teaching of English as the primary source, her historical reflection focused on four periods, inclusive of the initial years 
of each editor. They were from 1967 to 1969, under the editorship of Richard Braddock; from 1973-1975, Alan Purves; from 1977 to 1979, Roy O'Donnell; and finally from 1984 to 1986, Judith Langer and Arthur Applebee. During the first three years, Herrington found the articles were quantitative studies. They focused on investigating writing as texts, describing written texts linguistically or grammatically and evaluating written texts. The next three years was during the "troubled dream" period when researchers were questioning the quantitative research method and called for more qualitative research studies. At the same time, more articles were found to focus on sentence production and measuring writer's development in terms of syntactic complexity. Increased attention was also found on studies about the writing process. The third period of the study found several articles examining "writing as a sentence-generating activity." They included sentence-combining effectiveness, syntactic maturity measurement, and issues relevant to studying syntactic methodology. The authors also questioned "our values as teachers and readers of our students' writing" as well as writing processes. The last period covered in this study demonstrated the findings of using computers to write or to evaluate writing, extending more inquiry in syntactic features and writing quality, and viewing writing from a social perspective approach. Other studies also examined the differences between "basic" and "non-proficient" or "competent" and "proficient" writers.

The next study, conducted by Durst (1990), charted the terrain of writing research by analyzing the empirical studies of composition from 1984 to 1989. Durst analyzed the research on composition by examining what had been learned from the data collected. He specifically emphasized the growth areas issue, less interesting topics, and and topics of more interest. Durst discovered that from a total of 1,577 studies, 969 focused on composition. These studies were categorized into instruction, processes, text analysis, contexts, assessment, status surveys, writing and learning, and rhetoric. Durst further pointed out that almost 90 percent of the research focused on the first five categories. Durst also exclaimed that in his review, he found only about five percent of the research studies centered on minority writers. Additionally, most studies had the tendency of using elementary and college students as their research subjects whereas students from middle and high schools were largely ignored. Furthermore, he pointed out that the number of writing research in contextual studies was relatively small. From his review, Durst informed us of the future direction of research agenda.

Building upon Durst's study, the recent study conducted by Juzwik et al. (2006) took a broader look at the scope of recent research on writing, investigating the studies from 1999 to 2004. In this study, they examined the current trends and foci in writing research in the United States by looking at writing research from three dimensions: problems studied, population age groups studied and methods used. They searched 4,739 articles from ERIC, PsychINFO and Linguistics and Language Behavior Abstract databases but there were only 1,502 relevant articles analyzed. The result showed that, apart from using interpretive methodology in most of the research studies, the most currently studied problems in writing were context and writing practices; multilingualism, bilingualism, and writing; and writing instruction. In contrast, the least researched problems were writing and technologies, writing assessment and evaluation, and relationships among literacy modalities. Findings also indicated that the populated age groups being studied were undergraduate, adult, and postsecondary students, while the least studied age groups were preschool-aged students and middle and high school students. The result of Juzwik et al.'s study provides useful information for contemporary writing researchers and educators.

In L2 and EFL writing research, Silva and Brice (2004) examined published articles regarding research in teaching writing from 2000 to 2004 by including referred journal articles, book chapters, and books. Their study overviewed 1) basic research from composing processes, written texts, and assessment, and 2) applied research from content-based writing instruction, voice and identity, reading and writing, computers and technology, grammar and vocabulary, peer interaction, plagiarism, teacher response, and literature and film. They also discussed general issues and concerns, and pointed out the future direction for researchers.

Liou (2008) had recently presented a paper about EFL writing research in Taiwan, focusing only on three years she surveyed papers published on one local journal and proceedings of three English teaching conferences. Liou discovered that $46.9 \%$ of the studies centered on instruction-oriented research, 32.4\% focused on text-oriented research, $18.9 \%$ were on writer-oriented research and only $1.8 \%$ was on reader-oriented research. Liou's small scale study presented a rough picture of English writing research in Taiwan.

The above writing research in L1 and L2 covered studies on historical review (Hillocks, 1984; Herrington,1989), growth and interested research areas (Drust, 1990), teaching pedagogy (Silva and Brice, 2004), and the examination of current trends and foci (Juzwik et al.; 2006). To date, there is no thorough historical review of English writing research that examines the writing trends and foci in Taiwan. This paper aims to make significant advances in building a more comprehensive awareness in EFL writing research.

\section{Methodology}

\subsection{Data collection}

In order to make this task manageable and to present an overview of English writing research from 1989 to 2008 in Taiwan, two research assistants and I set limitation on the number of sources ( 5 altogether) from which we investigated 
the data: (1) Dissertation Abstracts International, (2) Electronic Theses and Dissertations System in Taiwan, (3) EBSCO Databases, (4) ERIC Databases, and (5) Education Full Text, The primary inclusion of these data sources was that authors usually considered these sources (with the exception of Dissertation Abstracts international and Electronic Theses and Dissertations System in Taiwan) as the major outlet for publishing their work internationally. In addition, readers would have easier access to these sources from most of the school libraries around the world. Furthermore, the studies discovered from the five data sources in one way or another have contributed an in-depth treatment in the specific area of English writing in Taiwan.

In general, studies which were conducted in Taiwan were included in the data analysis. In addition, both key words: "writing" and "Taiwan" were used in the databases to make sure the relevant studies were not being overlooked. The data collected from the five major sources sometimes overlapped. Extensive time was spent in order not to include the same theses or articles for data analysis. Table 1 shows the number of articles found from the five major data sources.

(Insert table 1 here)

\subsection{Coding}

Guided by Juzwik et al's (2006) study, the data were analyzed based on the general problems under investigated, the age groups being researched, the methodologies being implemented, and types of research being conducted at different grade levels. In analyzing the collected data with regard to the problems under investigated, two research assistants (a $\mathrm{Ph}$.D. student from the United States and the other, a Ph.D. candidate from Taiwan) helped worked on and created the categorization. The categories were coded preliminarily based on the title of each article. However, as Durst (1990) has discovered, "Many studies cut across categories; for example, much of the research on writing instruction focuses on the use of writing -process-based pedagogies in teaching composition. A number of writing-instruction studies examine classroom contexts or employ text analysis. In these cases of overlap, studies were categorized based on the dominant focus of the research (p.395)." Thus, in this study, if the title contained peers and computers, the original article would be located and reviewed carefully so as to decide whether it belonged to peer evaluation, or writing and technologies. For example, the study "Students' use of ideas provided by peers during prewriting discussions conducted on networked computers" was coded in the category of peer evaluation rather than writing and technologies. It was found from the original study that the major concern of the research was to examine the writing generated from the talk with their peers during computer-mediated prewriting discussions, and the quality of the peers' comments. Another example "The use of process writing and Internet technology in class: A focus on peer reviews" was not put in the category of writing process or writing and technologies because peer review was the major focus. The coding description for each researched problem can be found in table 2 .

(Insert table 2 here)

Similar to the study conducted by Juzwik et al., the age categories were coded based on the level of schooling. In Juzwik et al.'s study, the age category ranges from prior to school to adults. They were prior to school, elementary school, middle school, high school, undergraduate postsecondary and adults. However, in this study, since the educational system in Taiwan is quite different from that of the United States, we coded 12 age groups from the data. They were kindergarten, elementary school, junior high school, senior high school, vocational high school, junior college, military college, university of science and technology, medical college, regular university (science and technology are not the major focus of the university), graduate school, and adults (non-academic writers).

In terms of methodology being implemented, if the title contained a case study, it would be automatically put in the category of qualitative study. In addition, if the title of the study did not have any methodological phrase, the abstract was examined in detail to detect the use of methodology. Furthermore, if the research methodology or subjects were not clearly stated in the abstract, the original study would be located and examined in detail. Finally, if the study was put in the category of both qualitative and quantitative, it means that somewhere in the study, the author had stated that it was a blended study. If not, each abstract or the study itself would be examined carefully to determine which category it belonged in.

\section{Findings}

\subsection{The general problems investigated}

As a result of analyzing the collected data, the data was divided into fourteen categories. They were writing instruction, writing and technologies, peer evaluation, contrastive rhetoric, writing and metacognition, writing processes, e-mail exchanges, responding to student writing, writing assessment, writing anxiety, journal writing, collaborative writing, error analysis, cultural influences, and others.

From the five major sources of data analysis in this review, the most studied problems on writing research in Taiwan tended to focus on writing instruction, writing and technologies, and peer evaluation, whereas the problems least studied 
were error analysis and cultural influences. The general problems investigated by this writing research are shown as follows.

(Insert table 3 here)

\subsection{The population studied}

In Taiwan, university students were found to be the most frequently studied age group in existing English writing research. This age group was dominated as it was examined almost twice as much as the next frequently researched group, the senior high school level. Kindergarteners, military college students, and medical college students were found to be the least studied groups. Other students, such as vocational high school students and non-academic adults seldom became the subjects of writing research studies. The following table summaries the findings of the age groups being studied in Taiwan.

(Insert table 4 here)

\subsection{The methodology used}

From the data analyzed, with regard to methodology, it was important to note that both quantitative and qualitative research methodologies were almost equally adopted by writing researchers in Taiwan. The data indicated that quantitative method was implemented in $40 \%$ of the studies while qualitative method was implemented in $42 \%$ of the studies. $18 \%$ of the studies were found using both qualitative and quantitative methods.

(Insert Table 5 here)

\subsection{Types of research conducted at different grade levels}

From the five major data sources, there was only one study concerning the use of computer technology at kindergarten level. In terms of elementary schools, writing and technologies was still the major type of research, followed by writing instruction. With regard to junior high school levels, of the nine studies, three were about journal writing with the rest concerning writing instruction. Almost half of the research (20) conducted at senior high school level was still dominated by writing instruction. The rest of the studies consisted of writing and technologies, writing and metacognition, writing process, peer evaluation, teacher feedback, e-mail exchanges and journal writing. At vocational high school levels, writing assessment, error analysis, peer evaluation, writing instruction, and contrastive rhetoric were found from the data analysis. Research from the junior, military, medical college levels, and university of science and technology level showed writing and technologies, writing and metacognition were two major types of research. As for the regular university level, writing and technologies, peer evaluation, and contrastive rhetoric were the most studied types of research. At the adult level, two out of the four studies were writing and instruction, the third was e-mail exchanges and the fourth was collaborative writing. At the graduate level, writing and instruction, writing and technologies, and writing process were the most researched topics. The result of the analysis can be found in Appendix A.

\section{Discussion}

Focusing on the literature dated from 1989 to 2008, a 19-year time span, this paper examined the trends and foci from the collected data. It investigated the major problems, populations, methodologies and types of research conducted at different age groups in EFL writing research in Taiwan. The findings pointed out several important issues that deserve public attention.

First, in this study, data sources were drawn from Dissertation Abstracts International, Electronic Theses and Dissertations System in Taiwan, EBSCO Databases, ERIC Clearinghouse, and Education Full Text. The result showed a total of 188 studies, all conducted by Taiwanese researchers, on writing research. Among these 188 studies, only a small amount of research studies were published in the internationally referred journals. The rest were theses, dissertations, and reports. The small number of the English writing research articles indicates that more research in English language writing field is further required. This study advocates the growth of scholarship on EFL writing in Taiwan.

Second, from the findings concerning the problems being investigated in this paper, it has demonstrated that more and more writing instructors have become interested in using computer technology to help students compose in English. Given the rapid change of technology in modern times, computer technology has shortened the distance between countries around the world and it has opened up new and exciting possibilities for instructors to teach EFL writing. In recent years e-mail exchanges, online English learning, Plug-in Learning Object Module, Weblog networks implementation have been the central focus of EFL writing literature. It is expected that research in this field will continue to grow in EFL writing research in Taiwan.

Third, the age group being researched most was at the college level and the subjects being studied were mostly from English majors at colleges. This is partly because writing researchers in Taiwan are university professors and they tend 
to use their students as research subjects. It is also partly because writing is a mandatory course for English majors at universities in Taiwan. This study suggests curriculum developers in Taiwan should consider making non-English major college students take English writing as an obligatory course. This study also points out that increased amount of attention should be devoted to other age group of student writers, especially students from kindergarten, junior high school, vocational high schools, military college, medical college. Furthermore, apart from the above-mentioned age groups, master's students, doctoral students, foreign students, aborigines and adults have received scant attention from EFL writing researchers in Taiwan. More research in these fields also needs to be explored.

Fourth, the study revealed that within the past two decades, qualitative research methodology is being more frequently adopted by writing researchers in Taiwan. Both qualitative and quantitative methods were also used at the same time by $18 \%$ of the researchers to conduct their research. The increased number of qualitative research studies indicates that qualitative research has become a significant type of methodology in writing research in Taiwan. Researchers were no longer interested in testing hypotheses, instead, they turned to observe the class or participate in class, interview the students, and analyze the documents and materials so that more in-depth insights and contexts could be obtained from the writing class.

Fifth, from the collected data, research on writing anxiety was only found at college level, it is suggested that more research should be conducted by using younger students, including kindergarteners, elementary, and high school students as research subjects. These groups of students would probably have writing anxiety when asked to compose in English. In addition, from the data collected, of the six studies concerning writing assessment, only four portfolio assessment studies were found in one elementary school, one junior high school and two senior high schools. It is suggested that more research should focus on this field because learning to write is a long term process and it takes time and effort to accomplish a good written product. This study raises the issue of writing assessment for FL educators to think over.

Finally, this study has investigated the trends and foci of EFL writing research from five major sources within nearly two decades in Taiwan. While the study has provided important findings, future research should include more sources, including book chapters, books, local journal articles, and local conference papers devoted to adding information and insights to the existing body of EFL writing research currently available regarding Taiwan.

\section{References}

Archibald, Alasdair. \& Jeffery, G. C. (2000). Second language acquisition and writing: A Multi-disciplinary approach. Learning and Instruction, 10, 1-11.

Chang, Pi-chu.(2003). The effects of the process writing instruction on Taiwanese high school students' overall English writing ability. Unpublished Master's Thesis, National Taiwan Normal University, Taipei, Taiwan.

Chern, Chiou-lan. (2002). English language teaching in Taiwan today. Asia-Pacific Journal of Education, 22(2), 97-105.

Chiu, Ching-ya. (2005). The Effects of Cooperative Evaluation and Group Rewards with Writing \& Evaluation Cooperative Online Learning (WE-COOL) System on Senior High School Students' English Writing Achievement and Attitudes. Unpublished Doctoral Thesis, National Cha-Yi University, Cha-Yi, Taiwan.

Durst, Russel, K. (1990). The mongoose and the rat in composition research: Insights from the RTE Annotated Bibliography. College Composition and Communication, 41(4), 393-408.

Herrington, Ann, J. (1989). The first twenty years of research in the teaching of English and the growth of a research community in composition studies. Research in the Teaching of English, 23(2), 117-138.

Hillocks, JR., George. (1984). What works in teaching composition: A meta-analysis of experimental treatment studies. American Journal of Education, 93, 133-170.

Hillocks, JR., George. (1986). Research on written composition: New direction for teaching. Urbana, IL: National Council of Teachers of English.

Juzwik, M.M., Curcic, S., Wolbers, K., Moxley, K., Dimling, L., \& Shankland, R. (2006). Writing into the $21^{\text {st }}$ century: An overview of research on writing, 1999 to 2004. Written Communication, 23(4), 451-476.

Lee, Sy-ying. (2005). Facilitating and inhibiting factors in English as a foreign language writing performance: A model testing with structural equation modeling. Language Learning, 55(2), 335-374.

Leki, Ilona. (2003). Research insight on second language writing instruction. ERIC Digest.

Li, Li-te. (2003). The effects of implementing theme cycles on adult EFL writers.

Unpublished Doctoral Thesis. Tamkang University, Taipei, Taiwan. 
Liou, H. C. (2008). An overview of recent EFL writing research in Taiwan: technology use and workplace English. Paper presented at 25th Int'l conference on English teaching and learning in the ROC. CD-ROM proceedings. Chiayi: National Chung-Cheng University, May 3-4.

O’Brien, T. (2004). Writing in a foreign language: Teaching and learning. Language Teaching, 37, 1-28.

Silva,T., \& Matsuda, P. K. (Eds.). (2001). Landmark essays on ESL writing. NJ: Ahwah.

Williams, Jessica. (2005). Teaching writing in second and foreign language classrooms. McGraw-Hill.

You, Xiaoye. (2006). Globalization and the politics of teaching EFL writing. In Paul K.

Matsude, Christina ortmeier-hooper and Xiaoye Lafayette (Eds.), The Politics of second language writing: In search of the promised land (pp. 188-202). IN: Parlor Press.

Table 1. Number of Journals Found from Different Data Sources

\begin{tabular}{lc}
\hline Data Sources & Count \\
\hline Dissertation Abstracts International & 26 \\
Electronic Theses and Dissertations System & 117 \\
EBSCO Databases & 6 \\
ERIC Databases & 25 \\
Education Full Text & 6 \\
Journal of Second Language Writing & 3 \\
System & 4 \\
\hline
\end{tabular}

Table 2. Researched Problem Coding and Description

\begin{tabular}{|c|c|}
\hline Researched Problem & Coding Description \\
\hline Writing instruction & effectiveness of teaching strategies \\
\hline Writing and technologies & effects of computers and word processing on students' writing \\
\hline Peer evaluation & peer grading, peer editing, or peer commenting \\
\hline Contrastive rhetoric & rhetorical influences of the $\mathrm{L} 1$ on $\mathrm{L} 2$ \\
\hline Writing and metacognition & cognitive self-knowledge, what individuals know about their own thinking \\
\hline Writing processes & writers approaching writing \\
\hline E-mail exchanges & keypal exchanges \\
\hline Responding to student writing & teacher feedback \\
\hline Writing assessment (Portfolio) & assessing writing achievement and proficiency \\
\hline Writing anxiety & writing apprehension, writer's block \\
\hline Journal writing & writing journals or writing dialogue journals \\
\hline Collaborative writing & students compose writing together \\
\hline Cultural influences & writing influenced by cultural thinking and background \\
\hline Others & factors in writing ability, grammar, learner's writing strategy, attitudes \\
\hline
\end{tabular}

Table 3. Problems Investigated

\begin{tabular}{lc}
\hline Problems & Count \\
\hline Writing instruction & 46 \\
Writing and technologies & 32 \\
Peer evaluation (peer review, peer response) & 22 \\
Contrastive rhetoric & 15 \\
Writing and metacognition & 14 \\
Writing processes & 11 \\
e-mail exchanges & 8 \\
Responding to student writing (teacher feedback) & 6 \\
Writing assessment (Portfolio) & 6 \\
Writing anxiety & 5 \\
Journal writing & 5 \\
Collaborative writing & 5 \\
Error analysis & 4 \\
Cultural influences & 5 \\
Others (factors in writing ability, grammar, learner's writing strategy, attitudes) & 5 \\
\hline
\end{tabular}


Table 4. Age Groups Studied

\begin{tabular}{|c|c|}
\hline Age Groups & Count \\
\hline (Regular) university & 82 \\
\hline Senior high school & 44 \\
\hline Graduate school & 12 \\
\hline Junior college & 9 \\
\hline University of science and technology & 9 \\
\hline Elementary school & 9 \\
\hline Junior high school & 9 \\
\hline Vocational high school & 6 \\
\hline Adults (non-academic writers) & 4 \\
\hline Military college & 1 \\
\hline Medical college & 1 \\
\hline Kindergarten & 1 \\
\hline Table 5. Methodology Used & $\begin{array}{ll}\text { Total } & 187\end{array}$ \\
\hline Methodology & Count \\
\hline Quantitative study (experimental) & 59 \\
\hline Qualitative study & 46 \\
\hline Both qualitative \& quantitative & 34 \\
\hline Case study & 23 \\
\hline Questionnaire & 8 \\
\hline Action research & 7 \\
\hline Quasi-experimental design & 7 \\
\hline Interview & 2 \\
\hline Survey study & 1 \\
\hline
\end{tabular}




\section{Appendix}

Kindergarten Level

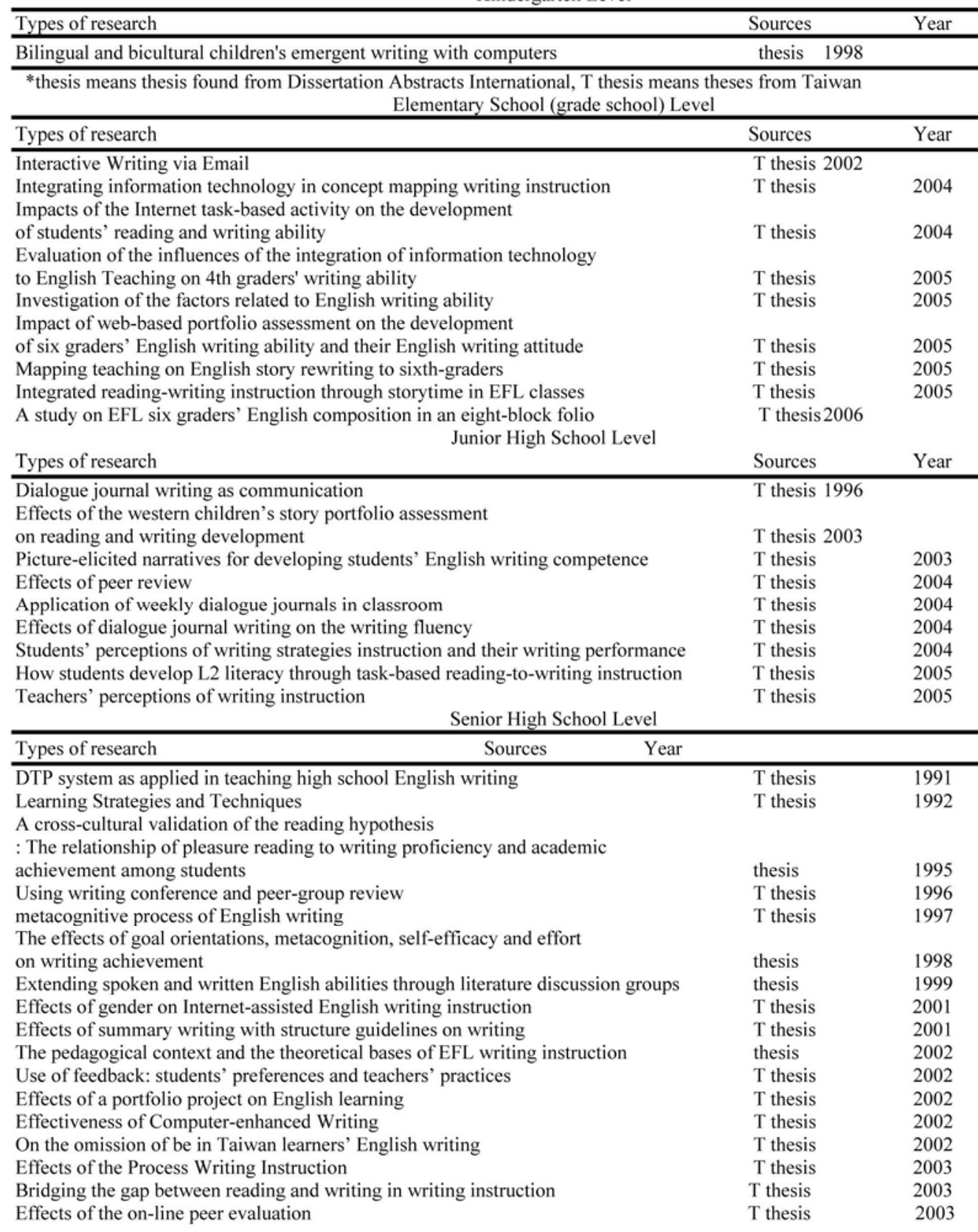


Effects of teaching organizing strategies in the pre-writing phase on W proficiency

T thesis 2003

T thesis 2003

T thesis 2003

T thesis 2003

T thesis 2003

T thesis 2003

T thesis 2003

$\mathrm{T}$ thesis 2004

T thesis 2004

T thesis 2004

Comparison of peer\& teacher evaluation

English teachers' practices and beliefs about writing instruction

Effects of English summary writing instruction on students' reading and writing abilities T thesis 2004

Improving coherence in students' compositions through instruction of topical development $\quad$ T thesis 2004

Effectiveness of metacognitive strategy instruction in English writing

Effects of adolescent-literature-letter reading and responding on English learning $\quad T$ thesis 2004

Integrating reading and writing in a senior high school classroom

Effect of multi-draft writing procedure on students' writing quality

and their attitudes toward writing and revision

A study on implementing writing portfolio in EFL classroom in senior high

English narrative writing process of Taiwanese senior high students

Effects of cooperative evaluation and group rewards with writing \& evaluation - cooperative

online learning (WE-COOL) system on students' English writing achievement and attitudes

Effects of story mapping on picture writing

Effectiveness of writing conferences in improving coherence in students' composition

Taiwan's high school English teachers' beliefs and practices in writing instruction

E-mail exchange project between non-native speakers of English

Effects of error correction on the English writing of senior high school students

Model-based writing instruction in senior high school English class

A metacognitive strategy training in an English writing program

The story behind English writing: Effects of three metacognitive learning strategy training

A study of the effects of dialogue journal writing and guided writing

on Taiwanese students' writing proficiency and writing apprehension

Vocational High School Level

Types of research

Effectiveness of peer evaluation

Error analysis of Chinese-to-English translation of students

Task types on EFL writing assessment

Translation from L1 into L2 and students L2 writing: coherence as a focus

A Comparison of three types of writing assessment

Effects of newspaper comics on English reading and writing

Junior College Level

Types of research

T thesis 2004

T thesis 2004

T thesis 2004

T thesis 2004

$\mathrm{T}$ thesis 2005

T thesis 2005

T thesis 2005

$\mathrm{T}$ thesis 2005

T thesis 2006

T thesis 2006

T thesis 2006

T thesis 2006

T thesis 2006

T thesis 2006

Sources Year

T thesis 2002

T thesis 2003

$\mathrm{T}$ thesis 2004

T thesis 2004

$\mathrm{T}$ thesis 2005

T thesis 2006

Sources Year

T thesis 1991

T thesis 1997

TESL-EJ 1997

LL 2000

T thesis 2002

T thesis 2004

Effects of reasoning skills on writing

Application of computer assisted instruction in teaching writing

The effect of the WebQuest writing instruction on learners' writing performance,

writing apprehension, and perception

*The role of peer-editing in helping ESL vocational college freshman

revise their writing descriptions grammatically

*Effect of structured Web activities and a Multimedia Sentence Structure Module

on single sentence English writing among freshmen international trade majors at

a vocation college

thesis 2004

thesis 2006

thesis 2007

* this vocational college means college of hospitality

Military College Level

$\begin{array}{ll}\text { Types of research } & \text { Sources Year }\end{array}$

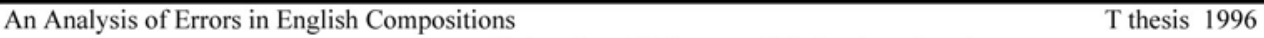

University of Science and Technology Level

Types of research

Sources Year

Enhancing English Communicative and Writing Ability

Beginning writers' perception and metacognitive knowledge of English writing

Strategy use and regulation in the writing tasks

Descriptive study of TVE teachers' and students' perspectives on writing instruction

Exploration of self-regulated learning strategies, goal orientation and self-efficacy on writing

Exploring EFL writers' self-regulation during composing process

Lexical collocations and their impact on the online writing of

English majors and non-English majors

Improving a college-level EFL writing class in Taiwan:

T thesis 2001

$\mathrm{T}$ thesis 2002

$\mathrm{T}$ thesis 2003

$\mathrm{T}$ thesis 2003

$\mathrm{T}$ thesis 2004

$\mathrm{T}$ thesis 2005

Report 2007 
From understanding students' writing anxiety to the implementation of an integrative process-product approach

thesis 2007

Types of research

Medical College

Sources Year

*Journal-writing in university pleasure-reading activities

Report 2000

*the medical college has changed to a national university in Taiwan, but the subjects were medical college students University Level

Types of research

Sources Year

Structures of English and Chinese narratives written by students

thesis 1989

A contrastive analysis of Chinese and English conjunctives

Intelligent CALL for EFL writing

An automatic text-analysis project for EFL writing revision

Can grammatical CALL help EFL writing instruction

Responding to student writing

Learning to critique and revise in a peer response group

Argumentative essays written by native speakers of Chinese and English:

A study in contrastive rhetoric

Efficacy of using writing groups to help students generate ideas for writing and revise drafts

Students' perceptions of their performance in peer response sessions

A study of verbal interaction in discussion groups in a writing class

L1 or L2 peer response sessions? Differences in verbal interaction between

a writing group that communicates in mandarin Chinese and one that uses English

Communicative devices used by EFL students in e-mail writing

A Protocol analysis of the process writing

Comparison of the effects between self-revision and peer- revision

Applying learning styles research to improve writing processes

Comparison between Chinese EFL students' peer response sessions

held on networked computers and those held in a face-to-face setting

When EFL writing students draft oral histories

Action research, learning styles, and EFL/ESL writing

Using electronic mail for English as a FL instruction

Effect of error correction on the grammatical structures of students" EFL writing

Examination of two anxiety constructs: L2 class anxiety and L2 writing anxiety

Feedback on student writing: taking the middle path

The influence of cultural schemata on writing

Language anxiety: differentiating writing and speaking components

Writer, the teacher, and the text: Examples from Taiwanese EFL college students

Internet assisting EFL writing learning: From learners' perspective

Students' use of ideas provided by peers during prewriting discussions conducted

on networked computers

L1-L2 Transfer of Rhetorical Patterns of Three University Students

Quantitative analysis of audiotaped and written feedback produced

for students' writing and students' perceptions of the two feedback methods

The nature of an EFL teacher's audiotaped and written feedback on student writing

Evaluating the impact of collectivism and individualism on argumentative writing

by Chinese and north American college students

Cultural thinking and discourse organizational patterns influencing writing skills

in an EFL Learner

Interlanguage variation on English past tense marking in students' writing

E-mail writing as a cross-cultural learning experience (email writing)

Using web articles for students' source-based writing

Exploring literary responses in an EFL classroom

How mind works to revise compositions

A study of English majors' preferences in invention

Investigating the metacognitive awareness and strategies of student writers

EFL teachers' responses to $\mathrm{L} 2$ writing

Effect of Rhetorical Analysis via Expository Models (instruction)

Motivation and attitude toward integrated instruction through technology

Peer review

Investigation of parts of speech in interlanguage: Subordinators in learners' writing

Critical literacy in an EFL context

Efects of rhetorical specification in writing assignments on EFL writing

Cohesive conditions to perceptions of writing quality

Effects of metacognitive strategy instruction on EFL writing

T thesis 1991

T thesis 1991

System 1992

CALICO 1992

thesis 1993

thesis 1994

thesis 1995

Report 1995

Report 1995

Report 1996

Report 1996

Report 1996

T thesis 1996

T thesis 1996

Report 1996

Report 1998

Report 1998

Report 1998

System 1998

T thesis 1998

thesis 1998

JSLW 1998

thesis 1999

LL 1999

Report 1999

Report 1999

Report 1999

T thesis 2000

$\begin{array}{ll}\text { TJ J } 2000 & 2000\end{array}$

report 2000

RTE 2000

BRJ 2001

T thesis 2001

System 2001

T thesis 2001

FLA 2001

Report 2001

Report 2001

Report 2001

Report 2002

$\mathrm{T}$ thesis 2002

thesis 2002

T thesis 2002

$\mathrm{T}$ thesis 2003

thesis 2003

2003

System 2003

T thesis 2003

The process of web-based reading and summary writing for EFL college novice writers T thesis 2003

Effects of reading and summarizing model essays on EFL writing

MBTI personality type and the utility of error correction among English majors in Taiwan

T thesis 2003

Report 2004

T thesis 2004

Interference of L1 on L2 in college students' writing

T thesis 2004 
A study on relative clauses

A measure of L2 writing anxiety: Scale development and preliminary validation

Effects of online peer response on EFL college writing

Taiwanese students' perception on peer review activity

The use of process writing and Internet technology in class: A focus on peer reviews

Students' reactions to teacher commentary and the relationship between the

reactions and writing proficiency in an EFL setting

Narrative structure in EFL stories of College English Majors

Effects of online conjunction units on EFL college students' writing

When students join the debate about the control of writing courses

Freshmen's compare/contrast writing process strategies and genre-specific strategies

Integration of culture into a college general English reading and writing class

English-major freshmen's narration writing strategies

The development and evaluation of a Plug-in Learning Object Module

:In the case of a web-based English writing course

Effects of automatic essay grading system and bilingual concordancer on Writing

A study of collocational error types in ESL/EFL college learner's writing

Impact of a Taiwanese/American e-mail exchange project

on Taiwanese participants' attitudes, cultural knowledge, and second language writing

Benefits of cooperative learning in weblog networks

Writing in English: Perspectives of an ethnic Chinese teacher and her students

Children's literature for reading and writing stories

An analysis of intertextuality in disciplinary writing

Interaction in EFL online classes: How Web-facilitated instruction influences

students' reading and learning

The application of double reinforcement learning strategy to online English writing

EFL college students' perceptions on collaborative writing

Investigation of the effects of incorporating peer feedback

into a focus-on-form EFL Writing Program

The effects of trained peer review on EFL students' revision types and writing quality

Instruction in conjunction usage and its influence on students' compositions

The use of a computer-based writing program: Facilitation or frustration?

Taiwanese students' negotiations with academic writing: playwrights and film directors

* means that the study covers students from different subjects at public university, private university and military academy

$$
\text { Adult Level }
$$

Types of research

Effects of model-based instruction on writing

Effects of implementing theme cycles

An exploratory study of e-mail application on FL writing performance
A study of students' construction of science knowledge: talk and writing

in a collaborative group

Graduate Student Level

Types of research

anguage proficiency and

A study of the relationship of ESL students' English language proficiency and
writing expertise and its implications to the curriculum of teaching ESL writing

Using collaborative writing creatively to teach reader-based prose

The connections between L1 and L2 writing performances

--From the perspective of writing expertise

Self-reported perspectives regarding academic writing among

Taiwanese graduate students specializing in TEFL

Writing from sources: summary and response writing

A study of students' attitudes toward and desired system

requirements of networked peer assessment system

English dictionary use in EFL writing tasks

Comparing EFL experienced writers' L1 and L2 writing processes

Text analyses and online material development for EAP graduate courses

Teaching of abstract writing in the field of applied linguistics discipline

Effects of online academic English materials on graduate students' writing:

Introductions in research articles of the applied linguistic disciplines

Writing for publication: Five novice Taiwanese scholars' composing processes

and an analysis of their writings of thesis introductions

Learning how to write a good MA thesis literature review: one graduate student
T thesis 2004

JSLW 2004

T thesis 2004

$\mathrm{T}$ thesis 2004

thesis 2004

thesis 2004

$\mathrm{T}$ thesis 2004

$\mathrm{T}$ thesis 2004

Report 2004

$\mathrm{T}$ thesis 2005

T thesis 2005

T thesis 2005

T thesis 2005

$\mathrm{T}$ thesis 2005

T thesis 2005

thesis 2005

Report 2005

thesis 2005

$\mathrm{T}$ thesis 2006

thesis 2006

thesis 2006

T thesis 2006

T thesis 2006

T thesis 2006

JSLW 2006

T thesis 2006

Report 2006

JSLW 2008

Sources Year

T thesis 2003

CALL J 2007

ER

Sources Year

thesis 1992

Report 1995

Report 1999

TPFLE 2001

$\mathrm{T}$ thesis 2002

$\mathrm{T}$ thesis 2004

$\mathrm{T}$ thesis 2004

T thesis 2005

$\mathrm{T}$ thesis 2005

$\mathrm{T}$ thesis 2005

$\mathrm{T}$ thesis 2006
T thesis 1998

IJIM 2003 